\title{
Anterior Mesencephalic Cap Dysplasia: Novel Brain Stem Malformative Features Associated with Joubert Syndrome
}

\author{
(D) F. Arrigoni, (DR. Romaniello, (DD. Peruzzo, (D) A. De Luca, (D) C. Parazzini, (D) E.M. Valente, (D) R. Borgatti, and (D) F. Triulzi
}

\begin{abstract}
SUMMARY: In Joubert syndrome, the "molar tooth" sign can be associated with several additional supra- and infratentorial malformations. Here we report on 3 subjects ( 2 siblings, 8-14 years of age) with Joubert syndrome, showing an abnormal thick bulging of the anterior profile of the mesencephalon causing a complete obliteration of the interpeduncular fossa. DTI revealed that the abnormal tissue consisted of an ectopic white matter tract with a laterolateral transverse orientation. Tractographic reconstructions support the hypothesis of impaired axonal guidance mechanisms responsible for the malformation. The 2 siblings were compound heterozygous for 2 missense variants in the TMEM67 gene, while no mutations in a panel of 120 ciliary genes were detected in the third patient. The name "anterior mesencephalic cap dysplasia," referring to the peculiar aspect of the mesencephalon on sagittal MR imaging, is proposed for this new malformative feature.
\end{abstract}

ABBREVIATIONS: $\mathrm{AMCD}=$ anterior mesencephalic cap dysplasia; $\mathrm{CST}=$ corticospinal tract; $\mathrm{IQ}=$ Intelligence Quotient; $\mathrm{JS}=$ Joubert syndrome; $\mathrm{SCP}=$ superior cerebellar peduncle

$\mathrm{T}$ he "molar tooth" sign is the distinctive imaging feature and a mandatory criterion for the diagnosis of Joubert syndrome (JS), a rare group of conditions characterized by a complex malformation of the midbrain-hindbrain. The molar tooth sign owes its name to the appearance of the pons and superior cerebellar peduncles (SCPs) on axial MR images, resembling a molar tooth. It is related to a moderate-to-severe vermian hypodysplasia, associated with a narrow pontine-mesencephalic junction and a thickened, elongated, horizontal SCP. ${ }^{1}$

\footnotetext{
Received March 9, 2017; accepted after revision June 30.

From the Neuroimaging Lab (F.A., D.P., A.D.L.) and Neuropsychiatry and Neurorehabilitation Unit (R.R., R.B.), Scientific Institute Istituto Di Ricovero e Cura a Carattere Scientific Eugenio Medea, Bosisio Parini, Italy; Department of Information Engineering (A.D.L.), University of Padova, Padova, Italy; Department of Pediatric Radiology and Neuroradiology (C.P.), "V. Buzzi” Children's Hospital, Milan, Italy; Department of Molecular Medicine (E.M.V.), University of Pavia, Pavia, Italy; Neurogenetics Unit (E.M.V.), Istituto Di Ricovero e Cura a Carattere Scientific Santa Lucia Foundation, Rome, Italy; and Department of Neuroradiology (F.T.), Scientific Institute Istituto Di Ricovero e Cura a Carattere Scientific Cà Granda FoundationOspedale Maggiore Policlinico, Milan, Italy.

This work was supported by the Italian Ministry of Health (Ricerca Corrente 2016-17) and by the European Research Council Starting Grant 260888.

Paper previously presented at: Annual Meeting of the European Society of Neuroradiology, September 13-17, 2017; Malmö, Sweden.

Please address correspondence to Filippo Arrigoni, MD, Neuroimaging Lab, Scientific Institute IRCCS Eugenio Medea, Via Don Luigi Monza 20, 23842 Bosisio Parini, Italy; e-mail: filippo.arrigoni@bp.Inf.it

-- Indicates open access to non-subscribers at www.ajnr.org

三 Indicates article with supplemental on-line table.

http://dx.doi.org/10.3174/ajnr.A5360
}

The typical clinical signs of JS (episodic hyperpnea, abnormal eye movements, developmental delay, and ataxia ${ }^{2}$ ) may be associated with heterogeneous neurologic and non-neurologic symptoms and defects in other organs, including the kidneys, retina, liver, and skeleton, ${ }^{1,3,4}$ giving rise to an extremely large spectrum of phenotypes, from relatively mild to severe conditions. ${ }^{5}$

JS is part of an expanding group of disorders called ciliopathies, caused by dysfunction of the primary cilium, a ubiquitous subcellular organelle that plays a key role in brain development and in many cellular functions. ${ }^{6}$ To date, $>35$ genes encoding for proteins of the primary cilium or its apparatus have been identified as causing $\mathrm{JS}^{5,7}$; however, many patients remain undiagnosed; thus, further genetic heterogeneity is suggested.

The variable degree of vermian hypodysplasia and the presence of associated supratentorial findings (hippocampal malrotation, callosal dysgenesis, migration disorders, hypothalamic hamartomas, cephaloceles, and ventriculomegaly) may further complicate the spectrum. ${ }^{8,9}$

We report on 3 patients from 2 different families ( 2 brothers with genetically defined JS and 1 unrelated girl), presenting an additional complex malformation of the brain stem characterized by an abnormal thick bulging of the anterior profile of the mesencephalon. DTI revealed that the abnormal tissue consisted of an ectopic bundle of white matter with a laterolateral transverse orientation, likely resulting from impaired axonal guidance mechanisms during the early stages of brain development. 

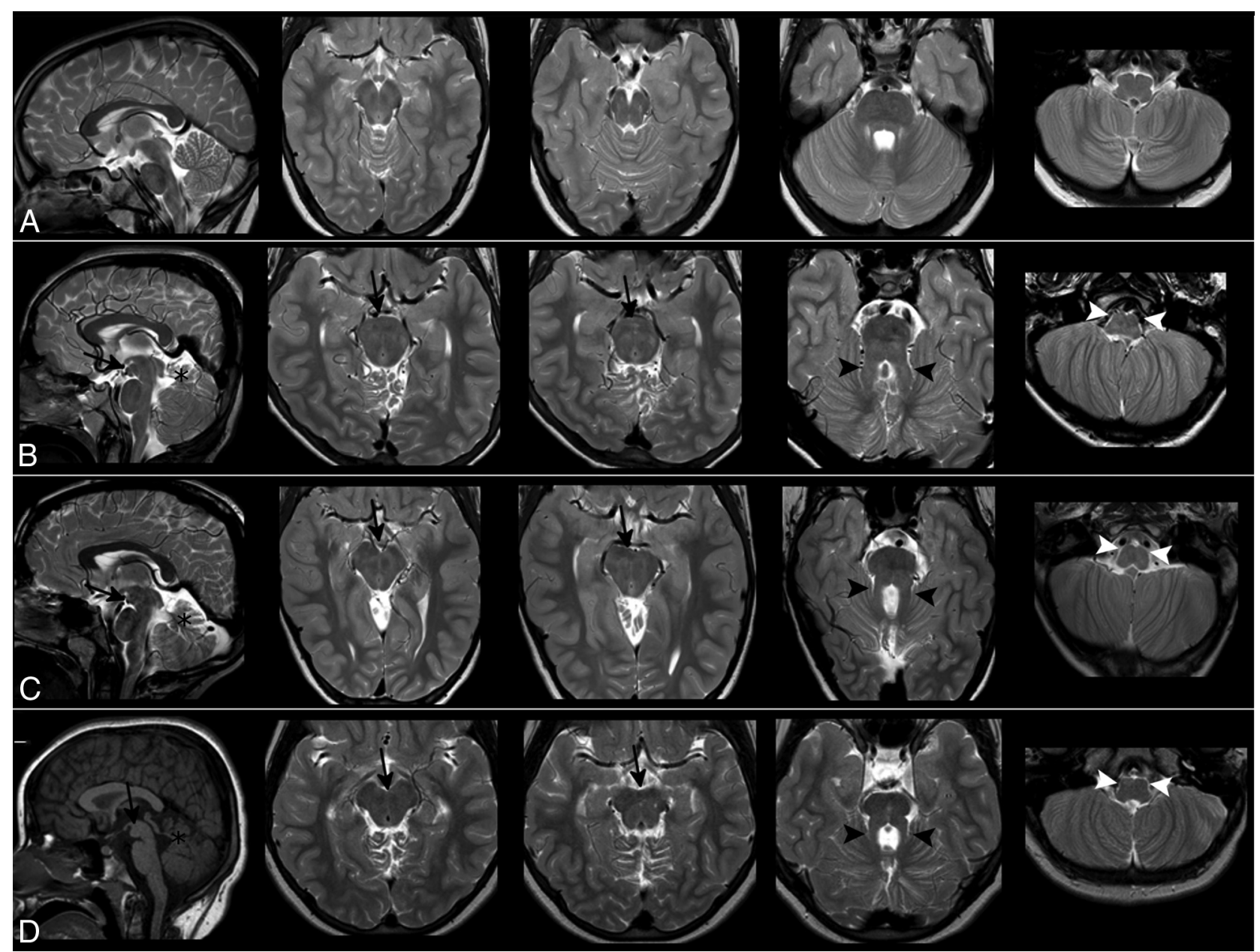

FIG 1. Morphologic findings. Images show T1- and T2-weighted sagittal and axial sections of a healthy subject (row A), patient 1 (row $B$ ), patient 2 (row C), and patient 3 (row D). In the 3 patients, the mesencephalon shows an anterior bulging (black arrows) that fills the interpeduncular cistern, visible both on sagittal and axial sections. The signal intensity of the abnormal mass is like that of white matter. Patients also share the classic features of mesial temporal sclerosis: cerebellar hypodysplasia (black asterisks), a thickened and horizontal SCP (black arrowheads), and hypoplasia of the medullary pyramids and inferior olivary nuclei (white arrowheads).

\section{MATERIALS AND METHODS \\ Neuroimaging Data}

Patients underwent MR imaging studies on either 3T (patients 1 and 2) or 1.5T (patient 3) scanners at 2 different institutions (Eugenio Medea Research Institute and "V. Buzzi” Children's Hospital). Axial and coronal T2-weighted (thickness, $3 \mathrm{~mm}$ ), axial and coronal FLAIR (thickness, $3 \mathrm{~mm}$ ), and 3D T1-weighted echospoiled gradient-echo images (voxel size, $1 \mathrm{~mm}^{3}$ ) were acquired. Balanced steady-state free precession sequences were acquired at $3 \mathrm{~T}$ to evaluate the cranial nerves. High-resolution DTI data (voxel size, $2 \mathrm{~mm}^{3}$; b-values, $0,300,1100 \mathrm{~s} / \mathrm{mm}^{2}$; number of directions, 32) were available for the 2 patients examined at $3 \mathrm{~T}$, while the third patient had low-resolution DTI (voxel size, $3 \mathrm{~mm}^{3}$; b-values, $0,1100 \mathrm{~s} / \mathrm{mm}^{2}$; number of directions, 15).

DTI data were preprocessed with the DIFF_PREP module of TORTOISE (https://science.nichd.nih.gov/confluence/display/ nihpd/TORTOISE) to remove motion and eddy current artifacts; then, correction of geometric EPI distortions was performed with DR-BUDDI using the dual-phase encoding acquisition. ${ }^{10}$ Fiber tractography was performed with TrackVis (http://www.trackvis. org $/ \mathrm{dtk} /)^{11}$ in patients 1 and 2 . We did not perform tractography in patient 3 because of the lower quality (ie, signal-to-noise ratio, resolution) of the data.

\section{Clinical and Genetic Data}

Neurologic, neuropsychological, and instrumental evaluations as well as genetic analysis were performed in all patients.

The local ethics committee approved the study. Written informed consent was obtained from all participating families.

\section{RESULTS}

\section{Neuroimaging}

The 3 patients showed a complex brain stem and cerebellar malformation, with normal findings in the supratentorial brain.

The main features of the common midbrain-hindbrain malformation were the following:

- A severe vermian hypodysplasia with a thickened, horizontal SCP determining a molar tooth shape of the superior brain stem on axial images (Fig 1)

- A flattening of the inferior olives and medullary pyramids (Fig 1) 

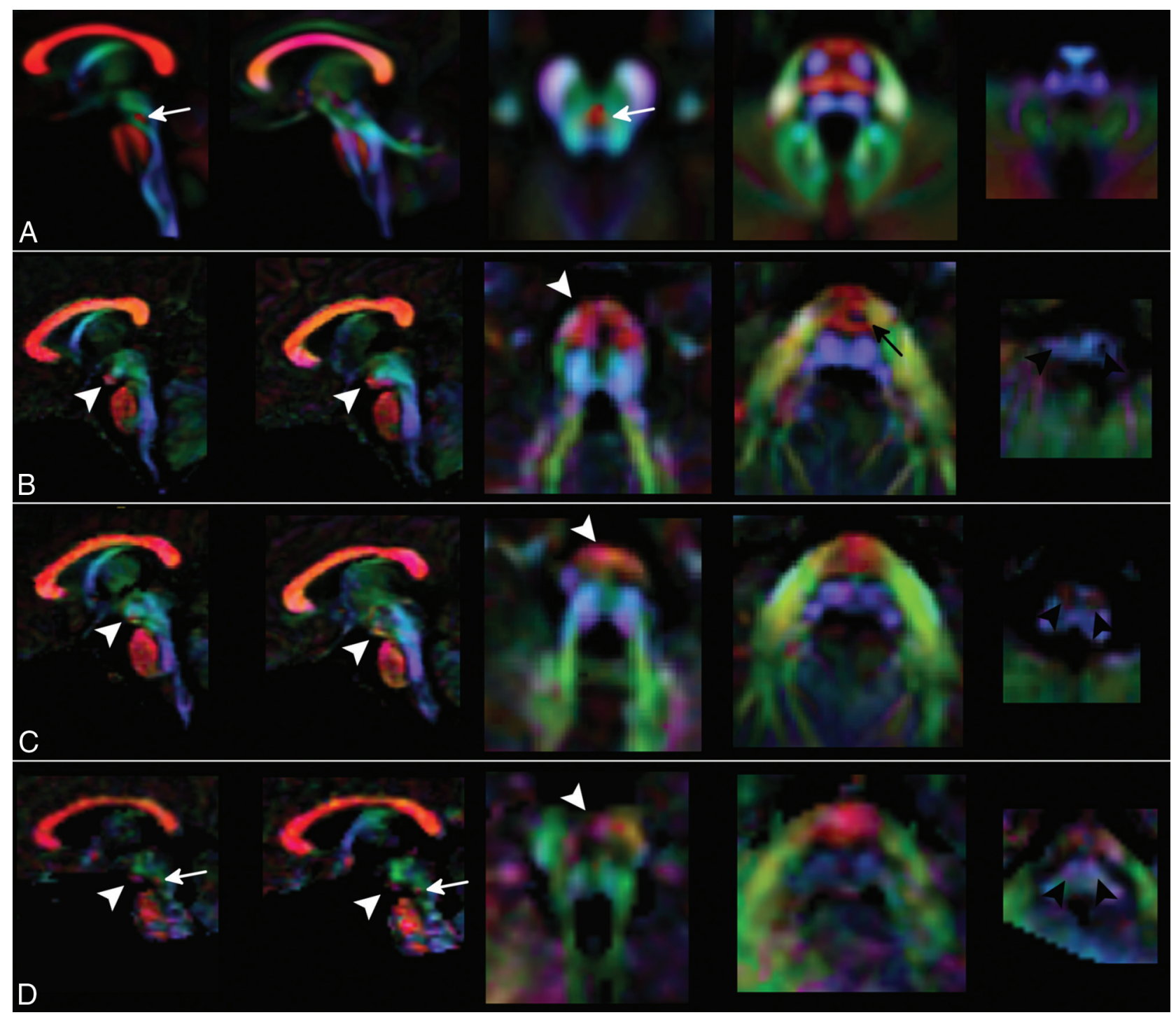

FIG 2. Color-coded DTI maps. Patients 1 (row $B$ ), 2 (row $C$ ), and 3 (row $D$ ) show an altered organization of white matter tracts if compared with a template of healthy subjects (row $A$ ). The anterior bulging of the mesencephalon corresponds to an area of transversely oriented diffusivity located anteriorly in the interpeduncular fossa (white arrowheads). CSTs in the pons are thinned (black arrow) or not clearly recognizable, and transverse pontine fibers appear as a unique bundle displaced in the anterior part of the pons. In the medulla, CST and lemnisci are hypoplastic/ atrophic and the olives are reduced in volume. The decussation of SCP (white arrow in the normal template) is absent in patients 1 and 2 and markedly thinned in patient 3 (white arrows in D). Red, green, and blue represent areas of transverse, anteroposterior, and caudocranial orientation of diffusivity and white matter, respectively.

- A narrow isthmus, with a thin pontine-mesencephalic junction

- A thickened tectum on the sagittal plane in patient 1

- An abnormal bulging of the anterior profile of the mesencephalon on sagittal planes. On axial images, such bulging resulted in a complete obliteration of the interpeduncular fossa, giving to the mesencephalon a more rounded anterior profile. Most interesting, the ectopic mass had the same signal intensity as white matter in all MR imaging weightings, and it did not look like a single, nodular interpeduncular structure (Fig 1).

- The third, fifth, sixth, seventh, and eighth cranial nerves could be recognized. The trochlear nerves were not identified, probably because of technical limits; extraocular muscles, including the oblique superior muscles, appeared regular in terms of signal intensity and volume. The optic nerves were thinned in patient 3 .
- Cranial nerves IX and X could be detected on balanced steadystate free precession sequences in patients 1 and 2. Patient 1 showed an agenesis of the left cranial nerve XII. The lower cranial nerves could not be assessed in patient 3 .

- Color-encoded DTI maps and tractography reconstructions revealed that the anterior mesencephalic bulging corresponded to a transversely orientated white matter tract in the interpeduncular cistern (Fig 2). On tractography, an apparent merging of corticospinal tracts (CSTs) with the abnormal mesencephalic bundle could be suspected.

- On color-encoded DTI maps, CSTs could be regularly recognized only until the upper part of the pons (Fig 2). On tractography, pontine transverse fibers and middle cerebellar peduncles appeared as a thick unique bundle anteriorly displaced in the pons (Fig 3). The SCPs were thickened, while the inferior cerebellar peduncles were atrophic in patient 1. SCP decussation was absent in patients 1 and 2, and it was thinned in patient 3 .

AJNR Am J Neuroradiol 38:2385-90 Dec 2017 www.ajnr.org 


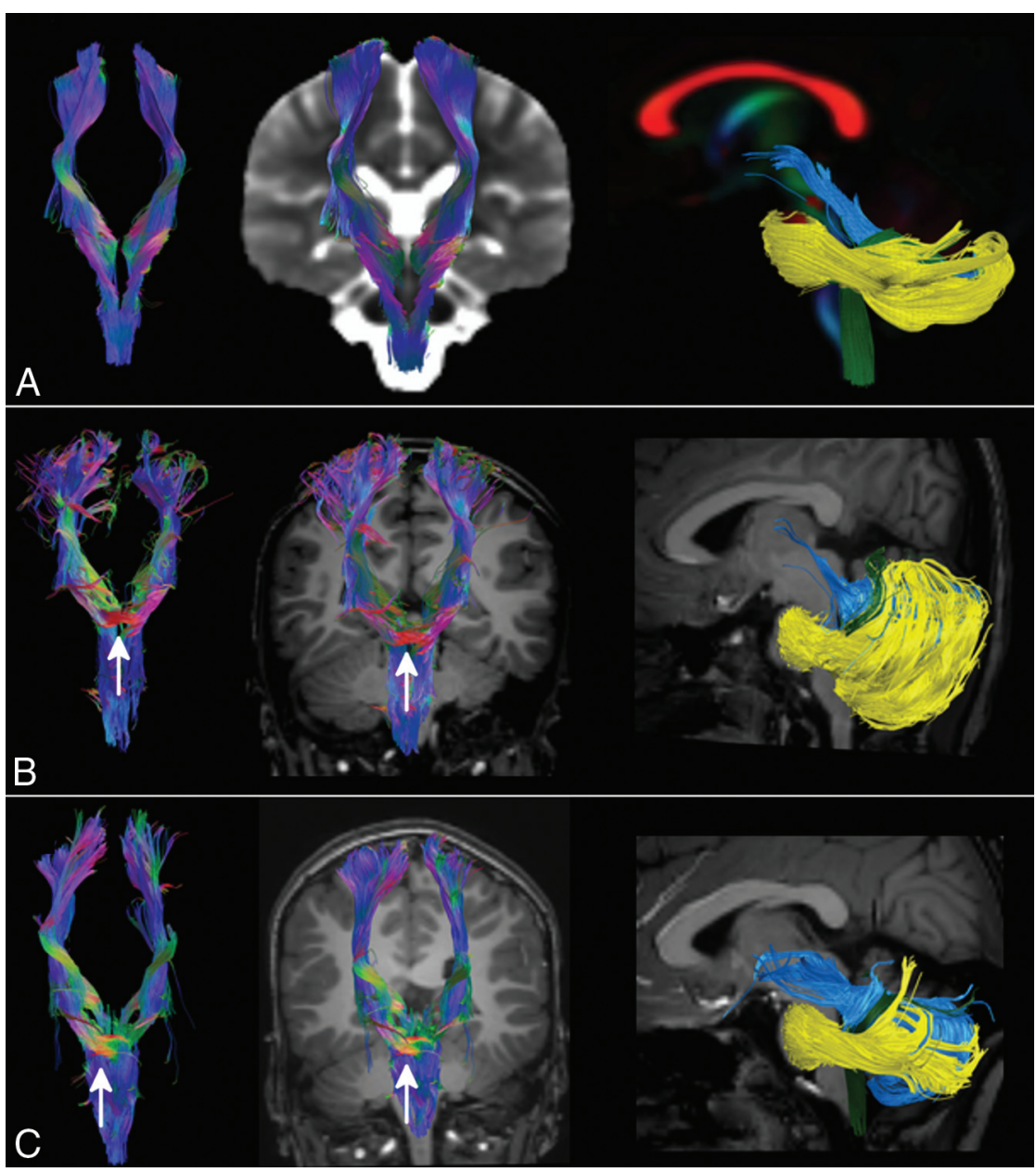

FIG 3. Tractography. CST (first 2 columns) and cerebellar peduncles (last column) were reconstructed with DTI data and the FACT algorithm from a template of healthy subjects (row $A$ ) and in patients 1 and 2 (rows $B$ and $C$ ). The ectopic mass seen on morphologic sections corresponds to a transvers bundle that seems to be located along the CST (white arrow). No transverse fibers are seen in the normal CST at the same level (row A). SCPs (light blue tract in the last column) of both patients are thickened and more horizontal than normal and do not pass through the anterior mesencephalon. The inferior cerebellar peduncles (green tract) in patient 1 are thinned, while in both patients, the middle cerebellar peduncles (yellow tract) are displaced anteriorly in the pons.

\section{Genetic Findings}

Clinical and genetic findings of the 2 siblings were reported in 2009 as part of a molecular genetic screening of the TMEM67 gene in patients with JS. They both were compound heterozygous for TMEM67 missense variants c. $1115 \mathrm{C}>\mathrm{A} / \mathrm{p}$. (T372K) and c.2345A $>$ G/p.(H782R), which were inherited from the healthy father and mother, respectively (Family COR32 in Brancati et $\mathrm{al}^{12}$ ). The third patient underwent next-generation sequencingbased analysis of a panel of 120 ciliopathy-related genes, ${ }^{13}$ which failed to identify any pathogenic variant.

\section{Clinical Findings}

Patient 1 is now a 14-year-old boy. He had impaired psychomotor development, with delayed motor acquisitions (able to walk independently at 6 years of age) and absence of expressive language. Currently, he can use sign language and is able to read and write words in uppercase letters. Good social skills are present. Neurologic examination showed diffuse hypotonia, nystagmus, oculomotor apraxia, dysmetria, severe oromotor dyspraxia, and gait ataxia. Cognitive testing showed moderate intellectual disability
(Wechsler Intelligence Scale for Children-Revised, Third Edition; Intelligence Quotient [IQ] $=46$ at performance subitems). Visual assessment detected a reduced visual acuity and bilateral optical nerve coloboma. The right kidney was polycystic and atrophic, while the left one showed compensatory hypertrophy at sonography. Liver biopsy at 8 years of age documented congenital hepatic fibrosis associated with mild portal hypertension, normal liver functioning, and the absence of esophageal varices.

Patient 2 is an 8-year-old boy. As with his older brother, he had delayed psychomotor development, walking unaided at 3 years of age and lacking any expressive language. Currently, he uses sign language with good social interactions and skills. Diffuse hypotonia, dysmetria, oromotor dyspraxia, and gait ataxia with moderate intellectual disability (Performance IQ $=41$ ) were evident at neurologic examination. A liver biopsy performed at 4 years of age demonstrated congenital hepatic fibrosis, hepatosplenomegaly, portal hypertension, and small esophageal varices. He also had an increase of transaminase and $\gamma$ glutamyltranspeptidase levels and thrombocytopenia secondary to hypersplenism.

Patient 3 is an 11-year-old girl, the only child of consanguineous healthy parents (second-grade cousins). She presented early in life with mild motor delay, severe intellectual impairment, marked visual deficits, and nystagmus. On the latest neurologic examination, she presented with severe intellectual disability with poor expressive language and social skills, diffuse hypotonia, and clumsiness. She had severe visual impairment (1/50 bilaterally), nystagmus, and roving ocular movements. Fundus oculi showed nerve optic hypoplasia and small vessels, and electroretinography could not elicit any response. Abdominal sonography and audiometric evaluation findings were normal.

Clinical findings and instrumental evaluation are summarized in the On-line Table.

\section{DISCUSSION}

The presence of an anterior mesencephalic bulging due to an ectopic transverse white matter bundle represents a new malformative pattern of the midbrain for which we propose the name "anterior mesencephalic cap dysplasia" (AMCD). This definition is adopted and adapted from a previously described malformation of the brain stem, pontine tegmental cap dysplasia, ${ }^{14}$ which shares some common features with AMCD. In both cases, the 
sagittal profile of the brain stem shows an abnormal "cap," which, in AMCD, is located anteriorly, at the mesencephalic level, while in pontine tegmental cap dysplasia, the cap is located posteriorly at the pontine level. Moreover, in both cases, on axial sections and DTI, the cap looks like a white matter ectopic bundle with a transverse laterolateral orientation.

Other diagnoses, like tumors, metastasis, or other proliferative disorders, could be easily excluded, considering their signal intensity and expansive/infiltrative features.

The presence of an interpeduncular mass in patients with JS was previously reported by Harting et al, ${ }^{15}$ who described 3 patients with a nodular structure within the interpeduncular fossa. Similar tissue can also be depicted, but not discussed, in several articles by Huppke et $\mathrm{al}^{16}$ and Alorainy et al. ${ }^{17}$ Interpeduncular masses in JS probably represent a continuum, but we believe that according to their appearance on both morphologic sequences and DTI, a distinction between pedunculated and nonpedunculated structures can be maintained. Interpeduncolar heterotopia is a nodular rounded structure, isointense to gray matter, with a peduncle that connects the mass to the brain stem, while AMCD is isointense to white matter, has no peduncle, and completely fills the interpeduncular fossa. Moreover, in AMCD, DTI confirmed the presence of an ectopic transverse white matter bundle anterior to the mesencephalon. Most interesting, according to tractographic reconstructions, the bundle appears to be in continuity with corticospinal tracts and may represent an ectopic decussation of the motor tracts. Careful interpretation of these findings is needed because the algorithm we used for tractography has limitations in resolving crossing or sharply angulated fibers, ${ }^{18}$ which are better handled by more sophisticated approaches, such as high angular resolution diffusion imaging (HARDI). Unfortunately, because of the characteristics of our protocol (low b-values, few diffusion directions), spheric deconvolution-based tractography did not improve the resolution of the tracts.

Anomalies in tract decussations (both CST and SCP) have been frequently described in neuropathologic reports of patients with JS. ${ }^{19-23}$ Moreover, the absence of CST decussation has been described in other conditions such as occipital encephalocele, Dandy-Walker malformation, Möbius syndrome, horizontal gaze palsy and progressive scoliosis, L1 syndrome, Kallmann syndrome, and trisomy $18,{ }^{24,25}$ while there is no report of aberrant ectopic mesencephalic decussation.

More recently, Poretti et $\mathrm{al}^{9}$ described a convex protuberance of the ventral contour of the midbrain due to a nodular structure in 13 of 110 patients with JS, expanding the findings from Harting et al. ${ }^{15}$ No DTI data are shown, and the lesions are interpreted as gray matter heterotopias; however, the possibility of ectopic white matter projections is left open.

Only a single case has been previously reported of a fetus with JS at 22 weeks' gestation, showing AMCD both at MR imaging and postmortem histology. ${ }^{26}$ As in our patients, in utero- and histology-based tractography confirmed the abnormal projection of the CSTs into the interpeduncular cistern. Both in the fetus and in our patients, the motor tracts were atrophic/barely recognizable in the pons and medulla.

The alternative hypothesis that the abnormal mesencephalic bundle represents an ectopic, aberrant white matter tract con- necting either the cerebral or cerebellar hemispheres cannot be completely discarded, even if it is not supported by tractography. We also hypothesized that the tract could represent the decussation of the SCP displaced anteriorly, but in patient 3, SCP decussation was present (even if uncommon in JS, the persistence of SCP decussation is not exceptional because it was already reported in neuropathologic studies ${ }^{21}$ ); in the 2 siblings, we could not identify a direct connection between SCP and the bundle. Pathologic confirmation is needed to fully understand the course of the abnormal tract and its origin.

Mirror movements, often associated with abnormal pyramidal decussation, resulting in bilateral CST projections to the spinal cord were not detected in our patients. ${ }^{27}$ Functional MR imaging during motor tasks would be of help to verify the decussation of the CST, but it could not be performed due to the insufficient cooperation of patients.

The 2 siblings had mutations in the TMEM67 gene, a ciliary gene that is expressed in the brain midline, hindbrain, retina, kidney, liver, and developing sphenoid bone and plays a fundamental role in centriole migration to the apical membrane and formation of the primary cilium. ${ }^{28}$ Most interesting, TMEM67 represents the gene for which the strongest gene-phenotype correlates have been drawn. ${ }^{29-31}$ In fact, nearly all patient with JS and the TMEM67 mutation have congenital liver fibrosis, variably associated with optic nerve or chorioretinal coloboma, retinal dystrophy, and renal involvement (COACH syndrome). ${ }^{32-34}$

Mounting evidence suggests a central role for the primary cilia in modulating neurogenesis, cell polarity, axonal guidance, and possibly adult neuronal functions. ${ }^{5,6}$ The lack of decussation of the CST and SCP reported in neuropathologic and DTI tractography studies of patients with JS suggested that defective primary cilia could also impair the process of axonal guidance, and the presence of an aberrant/ectopic white matter tract in patients with a proved ciliopathy can further support this theory.

Aberrant or ectopic white matter tracts have been detected in a wide spectrum of malformations involving the brain stem and corpus callosum, ${ }^{26,35-40}$ as a result of defects in axonal guidance or other mechanisms. The advent of high-resolution MR imaging and DTI along with the advances in genetic technologies helped to define and expand human disorders of axon guidance and will probably contribute to the discovery of many additional similar conditions in the future.

\section{CONCLUSIONS}

Through high-resolution MR imaging, DTI, and tractography, we demonstrated that nonpedunculated interpeduncular tissue in JS may represent an ectopic transverse white matter tract located in the mesencephalon, for which the name "AMCD" is proposed.

\section{ACKNOWLEDGMENTS}

We are grateful to patients and their family for cooperation in this study.

Disclosures: Filippo Arrigoni-RELATED: Grant: Italian Ministry of Health, Comments: Ricerca Corrente 2016. * Enza Maria Valente-RELATED: Grant: European Research Council, Comments: European Research Council Starting Grant 260888 to E.M.V.*; UNRELATED: Board Membership: Pediatric Research, Comments: Genetic Section Editor, Pediatric Research; Grants/Grants Pending: Telethon Italy, Italian

AJNR Am J Neuroradiol 38:2385-90 Dec 2017 www.ajnr.org 
Ministry of Health, Italian Ministry of University and Research.* *Money paid to the institution.

\section{REFERENCES}

1. Romani M, Micalizzi A, Valente EM. Joubert syndrome: congenital cerebellar ataxia with the molar tooth. Lancet Neurol 2013;12:894905 CrossRef Medline

2. Joubert M, Eisenring JJ, Robb JP, et al. Familial agenesis of the cerebellar vermis: a syndrome of episodic hyperpnea, abnormal eye movements, ataxia, and retardation. Neurology 1969;19:813-25 CrossRef Medline

3. Zaki MS, Abdel-Aleem A, Abdel-Salam G, et al. The molar tooth sign: a new Joubert syndrome and related cerebellar disorders classification system tested in Egyptian families. Neurology 2008;70:556-65 CrossRef Medline

4. Valente EM, Brancati F, Dallapiccola B. Genotypes and phenotypes of Joubert syndrome and related disorders. Eur J Med Genet 2008; 51:1-23 CrossRef Medline

5. Mitchison HM, Valente EM. Motile and non-motile cilia in human pathology: from function to phenotypes. J Pathol 2017;241:294-309 CrossRef Medline

6. Engle EC. Human genetic disorders of axon guidance. Cold Spring Harb Perspect Biol 2010;2:a001784 CrossRef Medline

7. Vilboux T, Doherty DA, Glass IA, et al. Molecular genetic findings and clinical correlations in 100 patients with Joubert syndrome and related disorders prospectively evaluated at a single center. Genet Med 2017 Jan 26. [Epub ahead of print] CrossRef Medline

8. Poretti A, Huisman TA, Scheer I, et al. Joubert syndrome and related disorders: spectrum of neuroimaging findings in 75 patients. AJNR Am J Neuroradiol 2011;32:1459-63 CrossRef Medline

9. Poretti A, Snow J, Summers AC, et al. Joubert syndrome: neuroimaging findings in 110 patients in correlation with cognitive function and genetic cause. J Med Genet 2017 Jan 13. [Epub ahead of print] CrossRef Medline

10. Pierpaoli C, Walker L, Irfanoglu MO, et al. Tortoise: an integrated software package for processing of diffusion MRI data. In: Proceedings of the International Society of Magnetic Resonance in Medicine, Stockholm, Sweden. May 1-7, 2010:1597

11. Wang R, Benner T, Sorensen AG, et al. Diffusion toolkit: a software package for diffusion imaging data processing and tractography. In: Proceedings of the International Society of Magnetic Resonance in Medicine, Berlin, Germany. May 19-25, 2007:3720

12. Brancati F, Iannicelli M, Travaglini L, et al; International JSRD Study Group. MKS3/TMEM67 mutations are a major cause of COACH Syndrome, a Joubert syndrome related disorder with liver involvement. Hum Mutat 2009;30:E432-42 CrossRef Medline

13. Roosing S, Romani M, Isrie M, et al. Mutations in CEP120 cause Joubert syndrome as well as complex ciliopathy phenotypes. J Med Genet 2016;53:608-15 CrossRef Medline

14. Barth PG, Majoie CB, Caan MWA, et al. Pontine tegmental cap dysplasia: a novel brain malformation with a defect in axonal guidance. Brain 2007;130:2258-66 CrossRef Medline

15. Harting I, Kotzaeridou U, Poretti A, et al. Interpeduncular heterotopia in Joubert syndrome: a previously undescribed MR finding. AJNR Am J Neuroradiol 2011;32:1286-89 CrossRef Medline

16. Huppke $\mathrm{P}$, Wegener E, Böhrer-Rabel H, et al. Tectonic gene mutations in patients with Joubert syndrome. Eur J Hum Genet 2015;23: 616-20 CrossRef Medline

17. Alorainy IA, Sabir S, Seidahmed MZ, et al. Brain stem and cerebellar findings in Joubert syndrome. J Comput Assist Tomogr 2006;30: 116-21 CrossRef Medline

18. Jeurissen B, Leemans A, Tournier J-D, et al. Investigating the prevalence of complex fiber configurations in white matter tissue with diffusion magnetic resonance imaging. Hum Brain Mapp 2013;34: 2747-66 CrossRef Medline

19. Friede RL, Boltshauser E. Uncommon syndromes of cerebellar ver- mis aplasia, I: Joubert syndrome. Dev Med Child Neurol 1978;20: 758-63 Medline

20. Yachnis AT, Rorke LB. Neuropathology of Joubert syndrome. J Child Neurol 1999;14:655-59; discussion 669-72 CrossRef Medline

21. Ferland RJ, Eyaid W, Collura RV, et al. Abnormal cerebellar development and axonal decussation due to mutations in AHI1 in Joubert syndrome. Nat Genet 2004;36:1008-13 CrossRef Medline

22. Juric-Sekhar G, Adkins J, Doherty D, et al. Joubert syndrome: brain and spinal cord malformations in genotyped cases and implications for neurodevelopmental functions of primary cilia. Acta Neuropathol 2012;123:695-709 CrossRef Medline

23. Poretti A, Boltshauser E, Loenneker T, et al. Diffusion tensor imaging in Joubert syndrome. AJNR Am J Neuroradiol 2007;28:1929-33 CrossRef Medline

24. Miyata H, Miyata M, Ohama E. Pyramidal tract abnormalities in the human fetus and infant with trisomy 18 syndrome. Neuropathology 2014;34:219-26 CrossRef Medline

25. ten Donkelaar HJ, Lammens M, Wesseling P, et al. Development and malformations of the human pyramidal tract. J Neurol 2004;251: 1429-42 CrossRef Medline

26. Mitter C, Jakab A, Brugger PC, et al. Validation of in utero tractography of human fetal commissural and internal capsule fibers with histological structure tensor analysis. Front Neuroanat 2015;9:164 CrossRef Medline

27. Welniarz Q, Dusart I, Roze E. The corticospinal tract: evolution, development, and human disorders. Dev Neurobiol 2017;77:810-29 CrossRef Medline

28. Dawe HR, Smith UM, Cullinane AR, et al. The Meckel-Gruber syndrome proteins MKS1 and meckelin interact and are required for primary cilium formation. Hum Mol Genet 2007;16:173-86 Medline

29. Smith UM, Consugar M, Tee LJ, et al. The transmembrane protein meckelin (MKS3) is mutated in Meckel-Gruber syndrome and the wpk rat. Nat Genet 2006;38:191-16 CrossRef Medline

30. Baala L, Khaddour R, Saunier S, et al. The Meckel-Gruber syndrome gene, MKS3, is mutated in Joubert syndrome. Am J Hum Genet 2007; 80:186-94 CrossRef Medline

31. Suzuki T, Miyake N, Tsurusaki Y, et al. Molecular genetic analysis of 30 families with Joubert syndrome. Clin Genet 2016;90:526-35 CrossRef Medline

32. Otto EA, Tory K, Attanasio M, et al. Hypomorphic mutations in meckelin (MKS3/TMEM67) cause nephronophthisis with liver fibrosis (NPHP11). J Med Genet 2009;46:663-70 CrossRef Medline

33. Iannicelli M, Brancati F, Mougou-Zerelli S, et al; International JSRD Study Group. Novel TMEM67 mutations and genotype-phenotype correlates in meckelin-related ciliopathies. Hum Mutat 2010;31: E1319-31 CrossRef Medline

34. Bachmann-Gagescu R, Phelps IG, Dempsey JC, et al. KIAA0586 is mutated in Joubert syndrome. Hum Mutat 2015;36:831-35 CrossRef Medline

35. Poretti A, Meoded A, Rossi A, et al. Diffusion tensor imaging and fiber tractography in brain malformations. Pediatr Radiol 2013;43: 28-54 CrossRef Medline

36. Briguglio M, Pinelli L, Giordano L, et al. Pontine tegmental cap dysplasia: developmental and cognitive outcome in three adolescent patients. Orphanet J Rare Dis 2011;6:36 CrossRef Medline

37. Haller S, Wetzel SG, Lütschg J. Functional MRI, DTI and neurophysiology in horizontal gaze palsy with progressive scoliosis. Neuroradiology 2008;50:453-59 CrossRef Medline

38. Caan MW, Barth PG, Niermeijer JM, et al. Ectopic peripontine arcuate fibres, a novel finding in pontine tegmental cap dysplasia. Eur J Paediatr Neurol 2014;18:434-38 CrossRef Medline

39. Sicotte NL, Salamon G, Shattuck DW, et al. Diffusion tensor MRI shows abnormal brainstem crossing fibers associated with $\mathrm{ROBO}$ mutations. Neurology 2006;67:519-21 CrossRef Medline

40. Arrigoni F, Romaniello R, Peruzzo D, et al. Aberrant supracallosal longitudinal bundle: MR features, pathogenesis and associated clinical phenotype. Eur Radiol 2016;26:2587-96 CrossRef Medline 